\title{
Silicon waveguides produced by wafer bonding
}

Poulsen, Mette; Jensen, Flemming; Bunk, Oliver; Feidenhans'I, Robert Krarup; Breiby, Dag Werner

Published in:

Applied Physics Letters

Link to article, DOI:

$10.1063 / 1.2158028$

Publication date:

2005

Document Version

Publisher's PDF, also known as Version of record

Link back to DTU Orbit

Citation (APA):

Poulsen, M., Jensen, F., Bunk, O., Feidenhans'l, R. K., \& Breiby, D. W. (2005). Silicon waveguides produced by wafer bonding. Applied Physics Letters, 87(26), 261904. https://doi.org/10.1063/1.2158028

\section{General rights}

Copyright and moral rights for the publications made accessible in the public portal are retained by the authors and/or other copyright owners and it is a condition of accessing publications that users recognise and abide by the legal requirements associated with these rights.

- Users may download and print one copy of any publication from the public portal for the purpose of private study or research.

- You may not further distribute the material or use it for any profit-making activity or commercial gain

- You may freely distribute the URL identifying the publication in the public portal

If you believe that this document breaches copyright please contact us providing details, and we will remove access to the work immediately and investigate your claim. 


\title{
Silicon waveguides produced by wafer bonding
}

\author{
M. Poulsen ${ }^{\mathrm{a})}$ \\ Department of Micro and Nanotechnology, Technical University of Denmark, Oersteds Plads, DK-2800 \\ Kgs. Lyngby, Denmark and Materials Research Department, Ris $\varnothing$ National Laboratory, Frederiksborgvej 399, \\ DK-4000 Roskilde, Denmark \\ F. Jensen \\ DANCHIP, Technical University of Denmark, Oersteds Plads, DK-2800 Kgs. Lyngby, Denmark
}

O. Bunk and R. Feidenhans'।

Materials Research Department, Risф National Laboratory, Frederiksborgvej 399, DK-4000 Roskilde, Denmark

D. W. Breiby

Danish Polymer Centre, Risø National Laboratory, Frederiksborgvej 399, DK-4000 Roskilde, Denmark

(Received 25 April 2005; accepted 21 November 2005; published online 20 December 2005)

X-ray waveguides are successfully produced employing standard silicon technology of UV photolithography and wafer bonding. Contrary to theoretical expectations for similar systems even $100 \mu \mathrm{m}$ broad guides of less than $80 \mathrm{~nm}$ height do not collapse and can be used as one dimensional waveguides to excite single guided modes at typical x-ray energies. () 2005 American Institute of Physics. [DOI: 10.1063/1.2158028]

There is a large interest in optical elements for hard $\mathrm{x}$-ray microbeam applications. ${ }^{1}$ Layered structures, operated below the critical angle for total reflection at the internal interfaces, are successfully used as waveguides confining the $\mathrm{x}$-ray beam in one dimension. ${ }^{2-4}$

Recently, also two-dimensional waveguides, essential for many microbeam experiments, have been demonstrated. ${ }^{5}$ These waveguides having a poly(methylmethacrylate) core and a $\mathrm{Cr}$ cladding were made by electron (e)-beam lithography in a relatively complicated process. We have produced one-dimensional $\mathrm{x}$-ray waveguides in a simpler way using standard silicon technology and wafer bonding. Channels were fabricated into double polished, 350- $\mu$ m-thick, 4 in. $\mathrm{Si}(100)$ wafers using conventional UV photolithography and etching techniques. Guides were made by closing the channels by a top wafer in a bonding process.

An oxide of approximately $100 \mathrm{~nm}$ thickness was thermally grown on the wafers in which the channels later was etched. The oxidation was performed as dry oxidation at $1000{ }^{\circ} \mathrm{C}$ with a constant flow of oxygen. The thickness of the oxide was adjusted by the oxidation time. The oxide layer served both as a protecting layer of the surface and as a part of the etching mask needed to etch the channels into the silicon. On top of the oxide a photoresist layer was spun, and the cavity pattern were transferred to the resist layer using negative photolithography. ${ }^{6}$ After developing, the pattern was transferred to the oxide layer using a reactive ion etch (RIE) with a high selectivity to both resist and silicon. This oxide layer is used as an etch mask, and a second RIE etch with high ratio selectivity or an advanced silicon etch (ASE) is performed to etch the final channel structures. The depth of the cavities (and hence, the height of the waveguides) was set by the etching procedure. The waveguides were then closed by hydrophobic fusion bonding ${ }^{7}$ of a $4 \mathrm{in}$. $\mathrm{Si}(100)$ wafer on top. The wafers were then annealed to $1000{ }^{\circ} \mathrm{C}$ for $30 \mathrm{~min}$ in order to increase the bond strength

\footnotetext{
${ }^{a)}$ Electronic mail: mpo@mic.dtu.dk
}

between them. The resulting bond strength is high and comparable to the bulk material. After annealing no voids (noncontacting areas) could be detected in infrared microscopy. The waveguides were then cut to the desired length. The x-ray radiation was coupled through the opening of the waveguide rather than a resonant beam coupling mechanism through a thin top layer. The fabrication and setup principle is illustrated in Fig. 1 (left).

The number of modes that can be excited in a waveguiding process increases with the size of the guide because the angular spacing $\Delta \Theta_{\text {in }}$ between the modes becomes very small. Therefore, for larger guides several modes are always excited and these optical elements behave more like simple apertures. Using standard silicon technology it is only possible to realize waveguides that are much wider than they are high and, hence, only exhibit distinct mode excitation in one direction. Furthermore, an array of waveguides with a chosen spacing can be realized and make, e.g., interference experiments with coherent beams possible. The expected number and positions of modes for the waveguide can be found
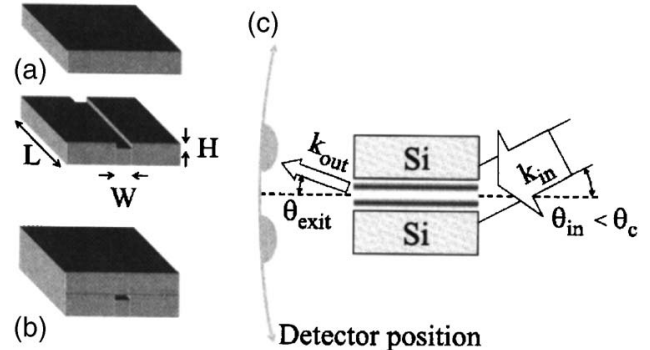

FIG. 1. (a) A channel is etched into a silicon wafer. (b) Hydrophobic bonding to a second wafer results in a two-dimensional waveguide. (c) Principle of waveguiding. The entrance of the guide is illuminated with monochromatic x-ray radiation at an angle $\Theta_{\text {in }}$ being smaller than the critical angle $\Theta_{c}$ for total reflection. The shadows inside the guide illustrate the spatial intensity variation of a mode being excited for a particular value of $\Theta_{\text {in. }}$. At the (far-field) detector position, the observed intensity is the Fourier transform of the intensity distribution at the exit of the guide. 

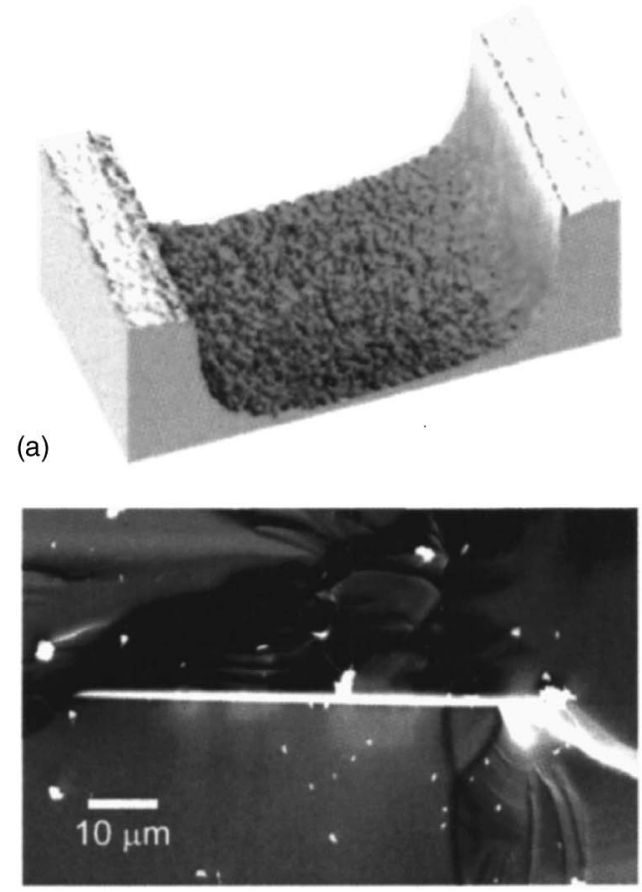

(b)

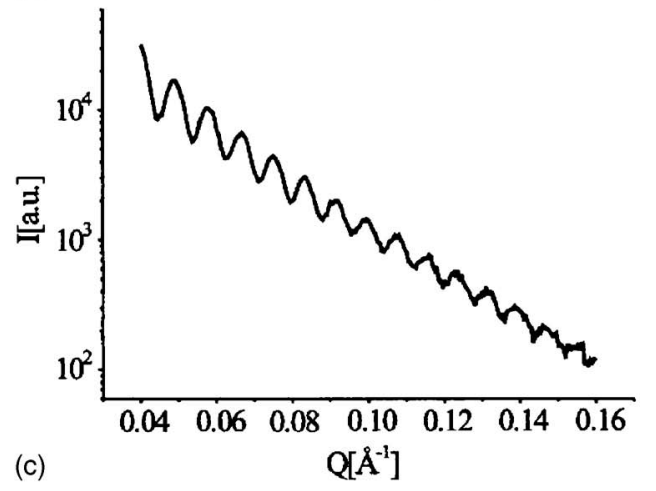

FIG. 2. (a) AFM image of a channel fabricated by photolithography and etched by thermal oxidation. The rms roughness in the bottom is approximately $10-30 \AA$. For standard silicon wafers rms is less than $5 \AA$. (b) SEM image of the entrance area of $100 \mu \mathrm{m} \times 74 \mathrm{~nm}$ guides. (c) X-ray reflectivity data measured in transmission geometry. The period of the observed oscillation corresponds to a height of the guide of $\sim 74 \mathrm{~nm}$.

using the Maxwell equations and the boundary conditions at the two air/silicon interfaces, ${ }^{8}$ and depend strongly on the dimensions of the cavities.

The appropriate dimensions for the height of the waveguides is in the nanometer range. For standard UV photolithography there is a lower limit in the lateral width of $1.5 \mu \mathrm{m}$, while the pattern length is limited by the size of the wafer. The quality of the pattern is very good, resulting in straight channels, but excitation of modes is only possible in one dimension since the guides are so wide that for typical $\mathrm{x}$-ray wavelengths and beam divergences a continuum of modes are always excited in this direction.

For having waveguides that are long enough to efficiently block the radiation not hitting the guide entrance we need at least a few millimeters long patterns for x-ray energies around $10 \mathrm{keV}$. The length of the cavities is typically $3 \mathrm{~mm}$. This is sufficient to observe the wanted waveguide effect and to absorb the unwanted direct beam.

The depth of the waveguides should be in the range of $20-100 \mathrm{~nm}$ and is controlled either by thermal oxidation, Downloaded 16 Jun 2010 to 192.38 .67 .112 . Redistribution subject
RIE or ASE, and is in the range of $25-100 \mathrm{~nm}$. The quality of the sidewalls and the bottom of the etched channels are important to successfully guide the major part of the incident intensity through the waveguides. We have investigated the etched structures by atomic force microscopy (AFM) before bonding and with scanning electron microscopy (SEM) after bonding. Furthermore, we have used x-ray reflectivity measurements in transmission geometry for short $1 \mathrm{~mm}$ guides to determine the exact depth of the waveguides. Typical results of these investigations are shown in Fig. 2. The structures were fabricated by thermal oxidation, and the rms roughness in the bottom is in the range 15-30 $\mathrm{\text { }}$. The areas between the channels, where the wafer is bonded, have a roughness of $10-15 \AA$. This is slightly more than for standard silicon wafers, but is sufficiently good for the bonding process. The SEM and $\mathrm{x}$-ray reflectivity results clearly demonstrate that the waveguides do not collapse, even for aspect ratios beyond 1:1000 with $100 \mu \mathrm{m}$ wide and less than $800 \AA$ high waveguides.

The roughness is induced during the fabrication process, but compared to other etching methods this enhanced roughness is negligible. As the roughness of the top wafer is less than that of the etched wafer to which it is bonded, one would not necessarily expect the intensity pattern created by the waveguide to be symmetric. This is also observed. Furthermore, when using thermal oxidation for etching, the channel walls will not appear as perpendicular sidewalls but rather as slightly rounded, smoothed curves.

When bonding silicon wafers at room temperature each wafer is elastically deformed to achieve conformity of the two surfaces, and if the wafers are not sufficiently flat, unbonded areas results. If a gap caused by nonuniform flatness is present between wafers, the condition for gap closing depends on the lateral extension, $R$, of the gap, and the wafer thickness, $t_{w}$. For the situation where $R>t_{w}$ the gap closing condition is given by ${ }^{7}$

$$
h<\frac{R^{2}}{\sqrt{\frac{2}{3} \frac{E t_{w}^{3}}{\gamma}}} .
$$

Here $h$ is the gap height, $E$ is the Young's modulus, ${ }^{6}$ and $\gamma$ is the surface energy of the bonding. For the opposite situation, $R<t_{w}$ :

$$
h<3.5(R \gamma / E)^{1 / 2} \text {. }
$$

The cavities are fabricated by bonding structured wafers to standard silicon wafers and for predicting whether the unstructured wafer covering the cavities will bond to the bottom of the cavity, ${ }^{7}$ we can use the earlier considerations as guidelines. The dimensions used for the cavities are highly asymmetric with lengths up to several centimeters and comparably narrow widths from 1.5 to $100 \mu \mathrm{m}$. The depth is from 20 to $100 \mathrm{~nm}$. If we insert these values in Eqs. (1) and (2) we would expect the cavities to be unstable with a high probability of closing, especially for the cavities with the largest width and smallest depth. This is not observed, and can probably be assigned to very asymmetric design.

$\mathrm{X}$-ray translation scans along the bonded interface with the beam transmitted through the cavities were performed, showing cavities at the expected positions having the nominal lateral dimensions. An example of a translation scan of an array of ten equally spaced $100-\mu \mathrm{m}$-wide cavities is given o AIP license or copyright; see http://apl.aip.org/apl/copyright.jsp 


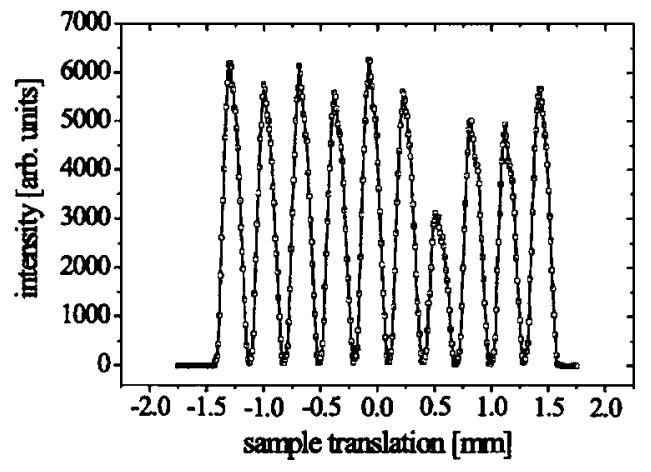

FIG. 3. X-ray translations scan of array of ten waveguides. With $\Theta_{\text {in }}=\Theta_{\text {exit }}=0^{\circ}$ the sample was horizontally translated through the beam at 10 $\mathrm{keV}$. The length of the guides is $3 \mathrm{~mm}$. The beam size was $20 \mu \mathrm{m} \times 100 \mu \mathrm{m}$.

in Fig. 3. The transmitted intensities are quite similar for the ten waveguides, with one exception. The lower intensity is probably due to silicon grains from the cutting process blocking the ends of the cavity. The fact that the transmitted intensity goes to zero in between the cavities demonstrates that the wafers are nicely bonded in the regions between the waveguides.

Preliminary measurements clearly demonstrate that the bonded cavities behave as waveguides, and typically we observed the first two to three modes. For some of the samples, the intensity distribution was not as symmetric as expected and also the peak positions were slightly displaced compared to what would be expected from the calculations of the positions. The effect might be due to the roughness difference between the bottom and the top of the cavity, edge defects or non parallel interfaces. An example of $100 \mu \mathrm{m} \times 74 \mathrm{~nm}$ waveguide intensities measured at beamline BW2, HASY$\mathrm{LAB}$, is shown in Fig. 4. For a guide with these dimensions, we expect from the theoretically calculations to observe three modes. One of the these modes is very close to the critical angle and therefore guided ineffectively. This corresponds very well to the observation of two guided modes.

In conclusion, we successfully produced waveguides using standard silicon technology. One-dimensional mode formation has been observed for $100 \mu \mathrm{m} \times 74 \mathrm{~nm}$ waveguides. Contrary to theoretical expectations even guides of height to width ratios beyond 1:1000 are stable against collapsing, and

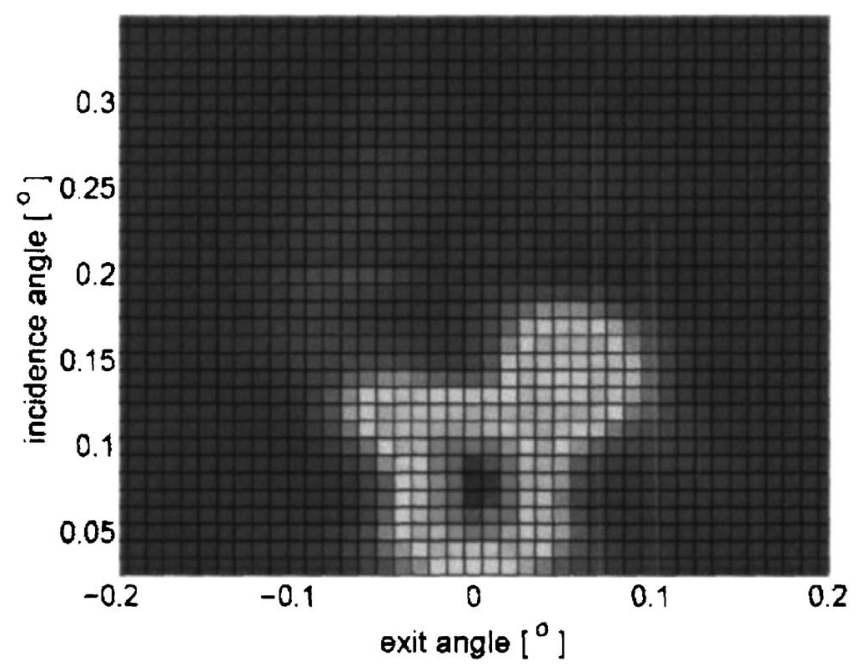

FIG. 4. Measured far-field intensity for a $74 \mathrm{~nm}$ high waveguide. First and second mode intensity can clearly be seen although the intensity of the second mode is distributed asymmetrically with respect to the $0^{\circ}$ exit-angle line.

these first experiments prove the possibility of fabricating waveguides using a relatively simple well established standard technique. Using e-beam lithography it might also possible to make true two-dimensional waveguides.

The authors thank the Danish Natural Research Council and DANSYNC for financial support and the HASYLAB staff for practical assistance during the surface $\mathrm{x}$-ray diffraction experiments.

${ }^{1}$ C. Riekel, Rep. Prog. Phys. 63, 233 (2000).

${ }^{2}$ A. Cedola, S. Lagomarsino, S. D. Fonzo, W. Jark, C. Riekel, and P. Deschamps, J. Synchrotron Radiat. 5, 17 (1998).

${ }^{3}$ M. J. Zwanenburg, J. H. H. Bongaerts, J. F. Peters, D. O. Riese, and J. F. van der Veen, Phys. Rev. Lett. 85, 5154 (2000).

${ }^{4}$ Y. Feng, H. Deckman, and S. Sinha, Appl. Phys. Lett. 64, 930 (1994).

${ }^{5}$ F. Pfeiffer, C. David, M. Burghammer, C. Riekel, and T. Salditt, Science 297, 230 (2002)

${ }^{6}$ M. Madou, Fundamentals of Microfabrication (CRC Press, Boca Raton, FL, 1997).

${ }^{7}$ Q. Y. Tong and U. Gösele, Semiconductor Wafer Bonding Science and Technology (Wiley, New York, 1999).

${ }^{8}$ D. Marcuse, Dielectrical Optical Waveguides, 2nd ed. (Academic, San Diego, 1991). 